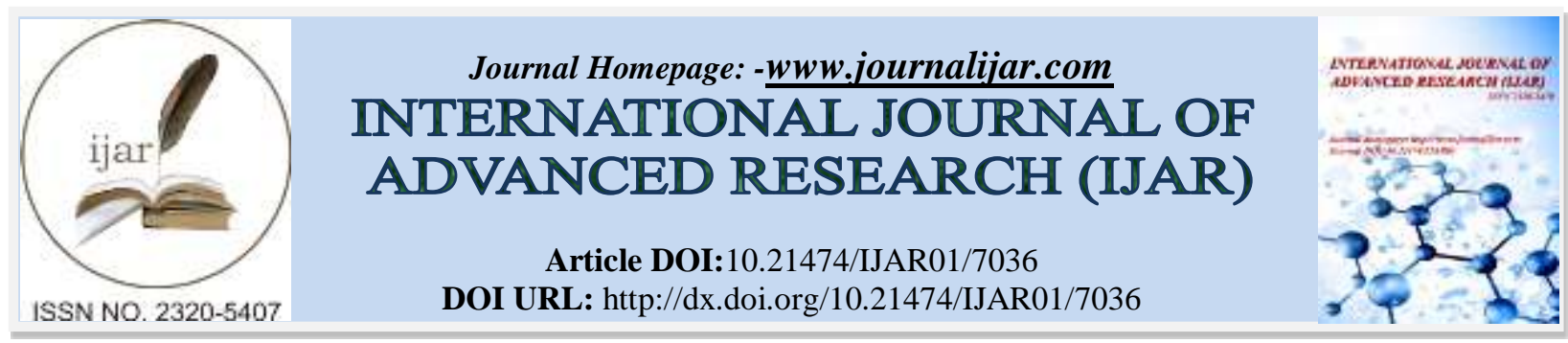

RESEARCH ARTICLE

\title{
A BINARY CODE AS A BASIS FOR UNDERSTANDING THE LOGICAL CONSTRUCTION OF CHINESE HIEROGLYPHIC GRAPHEMES.
}

Rita Kalko.

Drohobych Ivan Franko State Pedagogical University by street Vokzalny, 68 Sloviansk Ukraine 84109.

\section{Manuscript Info}

Manuscript History

Received: 05 March 2018

Final Accepted: 07 April 2018

Published: May 2018

Keywords:-

binary code, hieroglyphic grahpemes,

Chinese writing, Ba Gua's model, system of thinking, calligraphic lines.

\section{Abstract}

The problem of using binary code for understanding the logical construction of Chinese hieroglyphic graphemes is investigated. Considerable insight has been gained with regard to study Ba Gua's model that defines the main graphemes of the Chinese writing within three-bit system and two-dimensional space of the Cartesian plane. The evidence from this study towards the idea that using graphemes of the Chinese writing is determined by the logical construction of a standard model which can complicate from one-bit to three-bit system. According to the mathematical laws, the calligraphic lines can be represented as vectors that interact with each other. The Chinese writing as a cultural heritage whicn represents a multidimensional entity is described by graphemes as proto-complex numbers, the main task of which to transfer the dimensions of transcendental concepts into logical categories.

Copy Right, IJAR, 2018,. All rights reserved.

\section{Introduction:-}

A language as a system of thinking is widely considered to be the most represented in the Eastern tradition, codified not by phonemic, but by hieroglyphic means. In this context, it is important to outline the main linguistic approaches in the studies of the Chinese hieroglyphs. In modern linguistic science, there are two views of the eastern hieroglyph. According to the first, the hieroglyph is the result of the long evolution of the original petroglyph or pictogram. It has been identified as being fundamentally different from the rock paintings of the archaic people. In that connection, J. Friedrich noted, "The origin of the Chinese graphic symbols are drawings and their pictorial character has been observed in the earliest texts" (Friedrich J., 1966). A similar approach has been found in European scientific thought since the Great Discoveries and the first attempts to study and interpret the Han cultural tradition (Le Taoïsme, essais, 1950). A. Maspero's works and a number of others researchers' works were based on Eurocentrism. Generally, Eurocentrism was a priori acknowledged the secondary and inferiority of all newly discovered civilizations. Having not entering the discussion about this point of view, we should note that it is an external evaluation that contradicts authentic sources and presents Chinese civilization as based on the proto-science. If such thought was normal in the past, when China became a "sick man of Asia," today's scientific community will be regarded as archaic. Instead, an attempt is made to comprehend the Chinese writing as a formal way of fixing filologically the results of the development of reality with the help of the original natural and philosophical laws (Rezanenko V. F., 1996). 


\section{Theoretical Review:-}

It is important to note that the phenomenon of the eastern hieroglyphic writing is expedient to study on its internal logic. According to Chinese authentic tradition, Fu Xi (伏羲) invented writing by drawing eight trigram of Ba Gua (八卦), "Once Fu Xi saw the huge tortoise on the shore of the sea, on the armor of which were drawn Gua" (Birrell A., 2002).

This myth is very often interpreted as a reference to archaic divination on a tortoise shell (龜甲文), when the fire of the sacrificial hearth split it and the line of the fault, in conjunction with the chimeric pattern of the surface itself, created the archipelago of the "Taoist bird writing" (鳥 跡文). An indirect assumption for the term Ba Gua can be found in the classical Chinese literature: IX Chang Si Chi Zhuang (繫辭 傳) and I Jina Kanon of Changes (易經).

是故, 易有太極, 是生兩儀, 兩儀生四象, 四象生八卦, 八卦定吉凶, 吉凶生大業.

[Changes have a big limit. It generates Two images (兩儀) that form Four characters (四象) which are producing the Eight Trigrams (八卦). Everything is defined by means of the latter,].

Gua has the following two images: (兩儀). They are two main forces of the Oriental philosophy of Yin (陰) and Yang (陽). These two images are represented by horizontal lines: (- -), (-). Therefore, four characters represent four combinations of two lines: Old Yin 老陰 $\left(^{-}\right)$; Ian Young 少陽 $\left(^{---}\right)$; Young Yin 少陰 $\left(^{-}\right)$and Old Yang 老 陽 $\left(^{--}\right)$. Here follows the eight trigrams (八卦) i.e. the eight combinations of three lines: Qian 三 (乾), Dui 三 (兌), Lee $\mathbf{\Xi}$ (離), Zhen 至 (震), Xun $\mathbf{\Xi}$ (巽), Kan Yin and Yang (- -) (-), can be presented more convenient for the reader, in the case of using binary code: $(0,1)$, taking into consideration, the two images of each binary bit (one-bit); Four characters are two binary digits (two bits); Eight trigrams will be three binary digits (three-bits). In the European tradition, Fu Xi's eight trigrams, as illustrations of the binary number, were first mentioned by Joachim Bouvet in a letter to G.-B. Leibniz, and then in the work "Explication de l'arithmetique binaire" (Leibniz G. W., 1703). I.Bouvet attempted to identify the figure

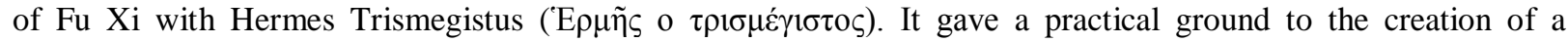
universal symbolic of G. Leibniz' language (Leibnyts H. V., 2010).

G. Ehrton is among contemporary scholars of the tradition of binary numerology in the system of signs. He carried out research on the study of the Incas khipu writing system (khig khipu and sp. Quipu - "knot", "knot knots", "account") (Independent., 2003). According to G. Erhton, the knoted writing of the Incas represents a 7-bit binary code. Taking into account 128 variations of 27 knitting methods and 24 possible colours of threads, we eventually get 1536 possible constructs. It more than twice exceeds the total number of Egyptian hieroglyphs and allows us to speak about the third kind of language, not oral or written, but through tactile sensations and visual perception (Kupriienko S. A., 2010).

Carlos Radicati di Primello (Primeglio. Carlos Radicati di) has established the following stages of distribution among the population of the Inka Empire: knowledge of the statistical khipu was common; knowledge of a simple ideographic khipu was accessible to a certain circle of people trained in this occupation; knowledge of the most perfect, refined ideographic khipu was available to a narrow circle of scientists (Amutah) and priests (Kokukamayokam) (Primeglio, 2006).

S. Kuprienko and others talk about khipu as a mathematical multidimensional system of writing. However, they note that without finding the Incas' "rosette stone" one cannot hope for success in its decoding. Since khipu and similar systematics existed in many regions of the globe, both in the West and in the East, this allows us to express the hypothesis of the possibility of describing the phenomenon of the eastern hieroglyphic system by means of a mathematical model in which the three-bit binary code of $\mathrm{Ba}$ Gua is updated with the main graphemes of Chinese writing. The mathematical model will be Descartes' plane, which is related to the nature of eastern writing. "... the Chinese book has fundamentally flat form - both materially and spiritually. Any classic treatise is a kind of scroll. A book common to Europeans, like a bunch of sheets, bundled together, could not have appeared in traditional China" (Lukianov A. E., 2000). The modern Descartes' coordinate system (rectangular coordinate system) in two dimensions is given by two axes. They are located at right angles to each other. The plane where the axis is located sometimes called the $x y$-plane. The horizontal axis is denoted by $x$ (abscissa) and vertical as $y$ (ordinate axis). All points in the Cartesian coordinate system make up the so-called Descartes space. The intersection point where the 
axes intersect is called the origin of the coordinates and is denoted as O. Accordingly, the $\mathrm{x}$ axis may be denoted as Ox, and the y axis is Oy. Straight lines drawn parallel to each axis at a distance of a unit length (units of length) form a grid starting from the coordinates. The point in the two-dimensional coordinate system is given by two numbers that determine the distance from the Oy axis (abscissa or X-coordinate) and from the Ox axis (ordinate or $y$-coordinate), respectively. Thus, the coordinates form an ordered pair (tuple) of numbers (x, y).

\section{Procedure And Methodology:-}

V. Rezanenko (Rezanenko V. F., 1996) first proposed the explanation of the eastern writing, as the semantics of the relations of the Taoist circle in the Cartesian plane. Unlike the idea of the cited researcher, we will try to use the authentic concept of Chinese writing as Ba Gua's semantic attitudes have been presented by Fu Xi and classical Oriental literature. Referring to the dictionary of the Kangxi radicals (康熙 部首), the rectangular coordinate system corresponds to the original radicals 1-3: one (-) (y⿳亠口冋) or the abscissa; vertical line ( I ) (gŭn) or axis of ordinates; the point ( \) (zhŭ) or O.

At this point we should be able to characterize each given bit system. Doing this we get, one-bit system which represents two images (兩儀). Two-bit system - four images (四象). Three-bit - eight trigrams (八卦). Each given system will be a subsystem of higher order. The set of characters belonging to it will be a subset of the set of higher-order characters. As it is easy to see, in the binary code (1.0) one-bit level denotes the yang sign (1). Jan (陽 ) (-) coincides with the Kangxi Radical 1 (one) (一). It repeats at higher order levels of Old Yang (老陽) (-) and Qian 三 (乾), that is, all of them (Yang (陽), Old Yang (老 陽) and Qian 三 (乾)) will be denoted by a horizontal line:

Then, to define the Kangxi radical of the Yin Sign (0), which points to the "emptiness" concerning Yang "completeness" (1) from the rectangular coordinate system we will define Yang as the axis of the abscissa, and Yin is the perpendicular axis of the ordinate or Radical Kangxi 2 (vertical line) ( I ). Accordingly, yin (陰) (_ I _), Old Yin 老 陰 $\left(\left.{ }^{-}\right|^{-}\right)$and Kun (坤) (三।三) will be marked by a vertical line:

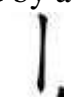

Due to the exhaustion of one-bit of space of two images (兩儀) Yin and Yang by Kangxi radicals 1 and 2 we go to the higher two-bit measurement of the Four symbols (四象). As mentioned above, one-bit space is a subset of highdimensional spaces over and its unchanged characters move to two-bit. So, Old Yang (老陽) and Old Yin (老陰) are denoted by Kangxi radicals 1 and 2. Ian Young 少陽 ( $\left.{ }^{--}\right)$, Young Yin 少陰 $\left(^{-{ }^{-}}\right.$) will be their combination (just broken line in Chinese writing): (horizontal, vertical line or HV) and mirror-symmetric as to it (vertical or horizontal line $\mathrm{VH})$ :

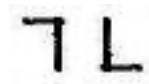

The two-bit space is described (Table 1.), and its signs of the Old Yang (老 陽), Old Yin (老 陰), Young Yang (少 陽) and Young Yin (少陰) are subsets of the three-bit space of Ba Gua.

Table. 1:-

\begin{tabular}{|l|l|l|l|}
\hline$--($ 老陽 $)$ & $---($ 少陽 $)$ & - (少陰 $)$ & - (老陰) \\
\hline- & 7 & $L$ & L
\end{tabular}

Having based on the authentic Fu Xi' theory of the origin of Chinese writing, a description of the three-bit space of $\mathrm{Ba}$ Gua using Cartesian plane must give the researcher the material of the graphemes (lines) of writing hieroglyphs, which is systematized by the natural philosophical theories of the Eastern worldview. 
That is, the system of binary three-bit code Ba Gua Qian trigram 三 (乾) will be marked by Kangxi radical one (1) ( 一), and trigram Kun $\mathbf{9}$ (坤) - by Kangxi Radical 2 (vertical line) ( I ). These are the most important signs that Wang Yangming (Wang Shouren) 王 陽明 (王國) (1472-1529) noted (王陽明., 1992).

According to Fu Yongh, the above-mentioned signs are the most commonly used in the Chinese writing (Wang H., 2003). So, the frequency which the horizontal line (including the stroke up) occurs most often in the characters is $30.30 \%$ and the vertical line is $19.38 \%$.

Definitely, it is difficult to draw a significant text with only two lines, except for the stylized Japanese signature of the Camo huāyā (花 押) or calligraphic style Kakuji (角 字) angular letters) which was used for the seals. Actually, the Chinese writing was formed much earlier at the transition from the style of writing lishu 隸書 to kaishu (楷書) and consisted of the following types of lines: direct, as well as simple and difficult-broken (ligatures). On account of the fact that Qian 三 (乾) and Kun (坤) gave us direct lines, in accordance, other Gua can form the ligatures. As an example of a simple broken line in the Chinese writing are the signs Young Yang (少陽). Young Yin (少陰) are described in the two-bit space. The three-bit space partly forms a complexly fragmented line. Therefore, Guo Li $\mathbf{\Xi}$ (離) will give the broken type ligature twice (Horizontal-Vertical-Horizontal Line or HVH)

Chen $\mathbf{z}$ (坎) - (Vertical-Horizontal-Vertical or VHV)

$$
\text { 与 } 3
$$

We need to find analogues of Ba Gua trigrams for the described two-bit space of simple broken lines of Young Yang (少陽) and Young Yin (少陰). According to the conjunctival relation of the Boolean algebra, the most probable correspondences will be Xun $\mathbf{\Xi}$ (巽) and Zhen 主 (震). The Xun trigram $\mathbf{\Xi}$ (巽) can also be formally described by a complex broken line (Horizontal-Horizontal-Vertical or HHV)

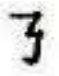

In the context of our study, there are two unanalyzed trigrams are left in the theory of Ba Gua: Duy Geny $\mathbf{\mathbf { I }}$ (a). They will resemble a complex broken line i. e. Zhen $\mathbf{\Xi}$ (震) and Xyun $\mathbf{\Xi}$ (巽) (Vertical-Horizontal or $\mathrm{VH})$ and (Horizontal -Vertical or HV).

Generally, they must be distinguished by a certain attribute, which can be the only unused symbol of Cartesian space, i. e. radical Kangxi 3 or the point ( $\backslash$ ). The point ( $\backslash$ ) forms the calligraphic sign "Hook" at the end of the vertical ( I ) or horizontal line (一). As for the horizontal line (一), the hook can only be drawn up, for the vertical ( I ) to the left and to the right. So, for Dui 至 (兌) we get a broken line (Vertical Horizontal-Hook or V-H-Hook).

A table of radicals indicates this possibility where Kangxi 6 is standed out by a "vertical with a hook" ( J ). It should be emphasized, that for horizontal line (一), it is possible to insert the hook only up and for the vertical ( I ) to the left and to the right. So, for Duo 至 (兌) we get a broken line (Vertical-Horizontally-Hook or B-H-Hook). Ghen (至 (艮) has two variants: Horizontal-Vertical-Hook (left and right):

The results on this study can be seen in Table 2

Table 2:-

\begin{tabular}{|c|c|c|c|c|c|c|c|}
\hline 三乾 & 泣坤 & 王 離 & 至坎 & 三巽 & 汪震 & 现艮 & 三分 \\
\hline- & 1. & L & 与 & 7 & $L$ & $J$ & $L$ \\
\hline & & & & 3 & & I & \\
\hline
\end{tabular}


We have devised strategy which at the surface analysis in the binary three-bit space of Ba Gua can distinguish 10 symbols of the graphemes of the eastern writing in the form of simple, simple and complex broken lines. For a modern researcher, they will resemble a geometric representation of mathematical vectors, which are also determined by the line and direction of the drawing. So, Kangxi 6's "vertical line with a hook" ( J ) even visually resembles a modern vector $(\downarrow)$. Since the vector represents a symbol of a complex number of type $X+I Y$ where $X Y$ are real numbers, and $-I$ is an imaginary unit, then simply-broken lines will represent a combination of two vectors in the form of their sum or difference. Due to the rules of vector mathematics, a single resulting vector can replace the sum or difference of two vectors:

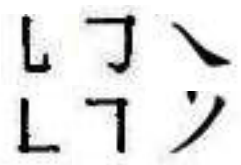

The result of the above-mentioned actions will be new variants of drawing of hieroglyphic lines: the flip to the right and the flip to the left. The latter can also be obtained as a consequence of the Kangxi 6 vectorial sum "vertical with a hook" J).

We use the folding lines for the analysis of the graphemes of Table 2 .

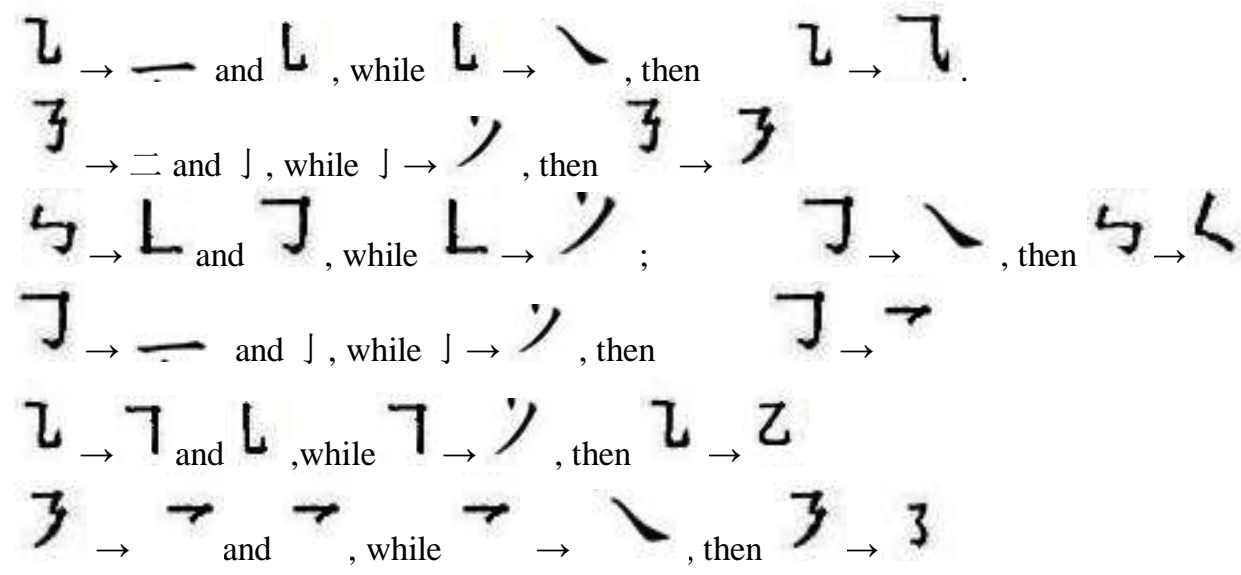

Whereas the Ghen 玉 (艮) and Dui 三 (兌) trigrams have mirror symmetry, their symbols are simply fragmented lines are also symmetric:

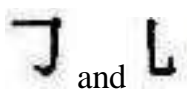

therefore, their symbols with folding lines should also be symmetric, because,

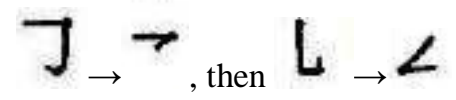

The obtained results are included in Table 3

Table 3:-

\begin{tabular}{|c|c|c|c|c|c|c|c|}
\hline 三 & 玉坤 & $\underset{\text { 離 }}{\mathbf{x}}$ & 至坎 & $\begin{array}{l}\overline{\mathbf{E}} \\
\text { 巽 }\end{array}$ & 全震 & $\begin{array}{l}\mathbf{\Xi} \\
\text { 艮 }\end{array}$ & 三分 \\
\hline$=$ & & I & 与 & 7 & $L$ & $J$ & L \\
\hline & & & & 3 & & I & \\
\hline & & 7 & $\angle$ & 3 & & $\rightarrow$ & $\angle$ \\
\hline
\end{tabular}




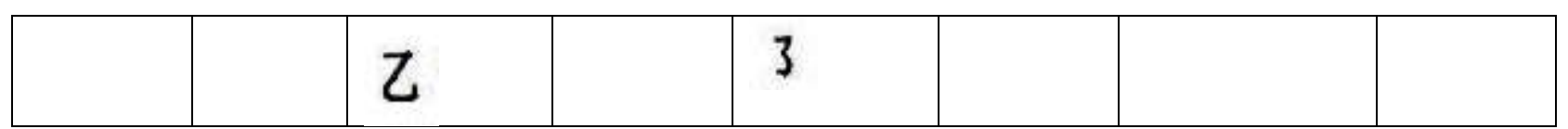

It should be noted, that the results obtained ( $~$, 乙, ᄀ, L) are found in Kangxi: Radical 5 (yĩ) or the second cyclic sign indicating the correctness of the study.

Additionally, a sign ( $\backslash$ ) point Radical 3 (chu) can be distinguished in the Cartesian plane. It enters as "Hook" in the final table 3 in the following symbols:

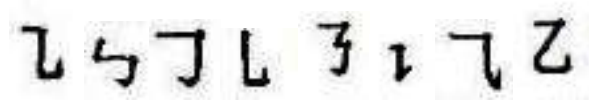

According to Fu Yonghe's research, Radical 3 (chu) as a separate symbol is the least found in all graphemes. So, the frequency of his quotation in the Kangxi Dictionary is 10, whereas, for example, Radical 140 (忺) (căo) grass is 1902 times. In the context of our research, the above-mentined symbol as a separate sign falls out of sight, since Cartesian plane is two-dimensional, and the sign ( $\backslash$ ) is a symbol of zero-dimensional space. Summarizing, we can

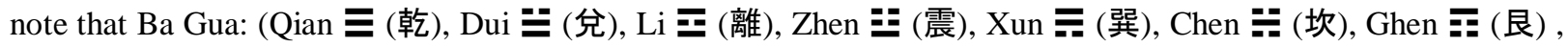
Kun $\mathbf{\Xi}$ (坤)) determine the 20 major graphemes of Chinese writing (19 in Table 3 plus "point").

As a result, our logical construction is organized as follows: combining the results of Table 1, Table 2 and Table 3 we will get general results in the Table 4. It can be explained as formalization of the Eastern world outlook in the phenomena of the graphemes of the Chinese writing (reviewed till 3-bit code). The indicated rows (to 10) are on the vertical axis. The numbers of cells in a row (from 2 to 8 ) are on the horizontal axis of the abscissa. The number of a single cell is indicated in the lower right corner:

Table 4:-

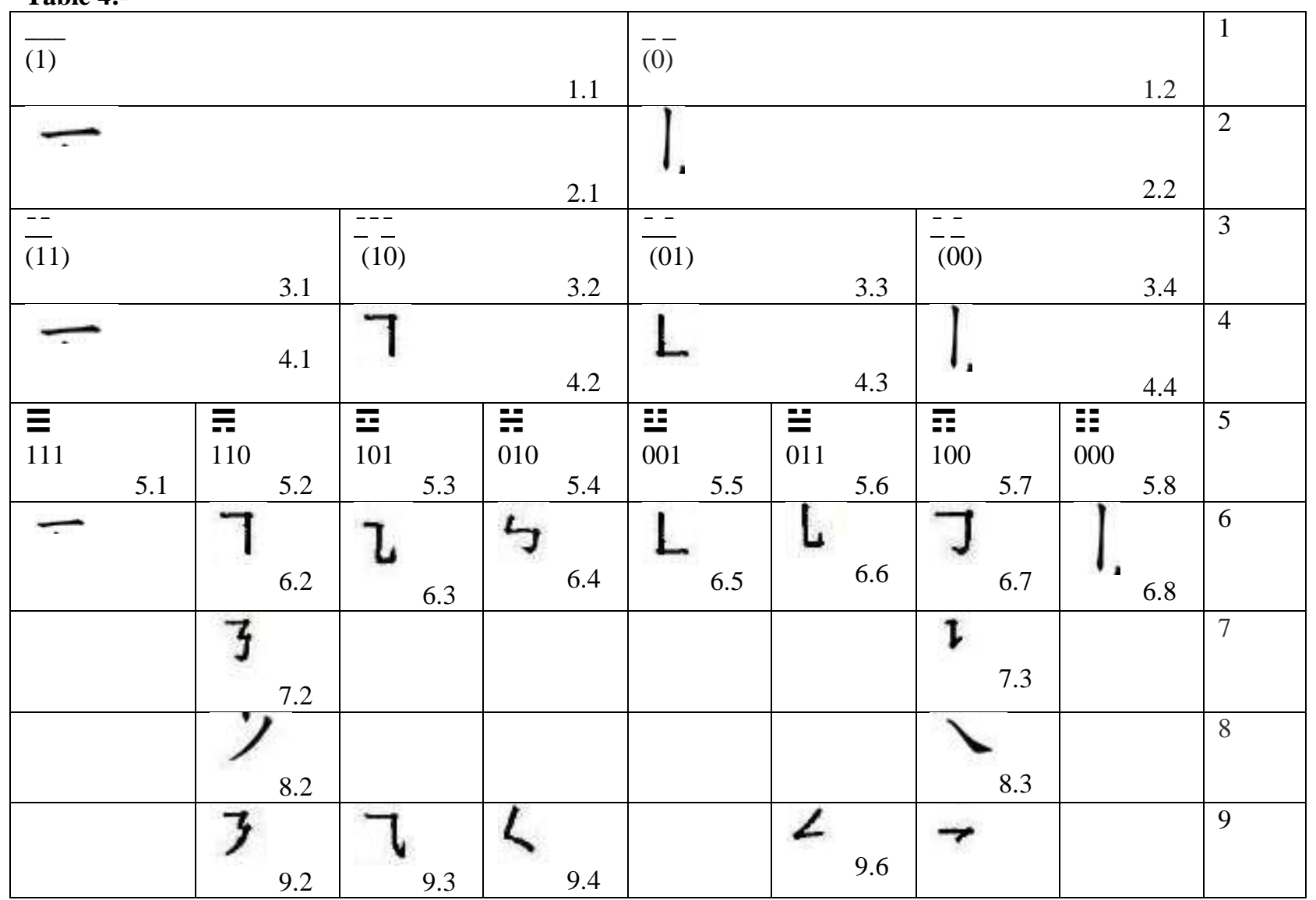




\begin{tabular}{|l|l|l|l|l|l|l|l|l|}
\hline & & & & & & 9.7 & & \\
\hline & 3 & 乙 & & & & & & \\
& & & & & & & & \\
\hline 1 & 2 & 3 & 4 & 5 & 6 & 7 & 8 & \\
\hline
\end{tabular}

The 0-bit code is a non-differentiated understanding of reality. It is not represented by any symbol. Therefore, it is not shown in Table 4. The rows 1 and 2 of Table 4 present a 1-bit code, when all phenomena are divided into Yang (1) and Yin (0). Accordingly, graphemes ( - ) and ( I ). Next, the 2-bit code in the rows: 3 and 4 and its possible variants consists of doubling the previous graphemes in the extreme positions and combining the contents of the adjacent cells.

Thus, the contents of cells 1.1 and 1.2 are doubled. It is written in 3.1 and 3.4. The content of 1.1 is added to 1.2 and recorded in 3.2; content of 1.2 is added to 1.1 and recorded in 3.3. Graphemes are also composed in such a way. Contents of 2.1 into 4.1; 2.2 into 4.4. Contents of 2.1 and 2.2 into 4.2, and 2.2 and 2.1 into 4.3. A 3-bit code will be in the rows: 5 and 6 . Similar signs $(1 ; 0)$ we add into extreme cells 3.1 and record the result into 5.1 , and 3.4 in 5.8. The content of adjacent cells is united. $3.1+3.2=5.2 ; 3.2+3.3=5.3 ; 3.3+3.4=5.4 ; 3.4+3.3=5.5 ; 3.3+$ $3.2=5.6 ; 3.2+3.1=5.7$. Accordingly, graphemes are also composed. $4.1+4.2=6.2 ; 4.2+4.3=6.3 ; 4.3+4.4=$ $6.4 ; 4.4+4.3=6.5 ; 4.3+4.2=6.6 ; 4.2+4.1=6.7$. Variants of recording graphemes of the Eastern writing are in the cells 7.2 and 7.7. For example, hook writing is different in 6.7 and 7.7 (left or right). Subsequently, the vector sum of the graphemes: ( - ) and $(\mathrm{I})$ is used. It gives inclined lines in the cells 8.2 and 8.7. Taking into account the latter, according to the laws of logical analysis, the graphemes in columns: 6.2, 6.3, 6.4, 6.6, 6.7 are rewritten and recorded in cells: 9.2, 9.3, 9.4, 9.6, 9.7 and also 10.2 and 10.3. The described structure resembles the deterministic work of a finite automaton and can be the basis for the algorithmic system of calculations in computer linguistics.

\section{Conclusions:-}

Our research has led us to conclude the following:

1. Ba Gua defines the main graphemes of Chinese writing in three-bit and two-dimensional space of the Cartesian plane.

2. Graphemes of Chinese writing are determined by the logical construction of a standard model can complicate from one-bit to three-bit system.

3. The calligraphic lines can be represented as vectors that interact with each other.

4. The Chinese writing as a heritage of culture represents a multidimensional entity, which can be described by graphemes as protocomplex numbers.

5. The graphemes as protocomplex numbers can transfer the dimensions of transcendental concepts into logical categories. 


\section{References:-}

1. Birrell A. Chinesische Mythen Philipp Reclam jun / Anne Birrell. - Stuttgart: Verlag, 2002. - 160 c.

2. Friedrich J. Geschichte der Schrift / Johannes Friedrich. - Heidelberg: Carl Winter, 1966. -408 c.

3. Independent. June 24, 2003.

4. Kupriienko S. A. Kipu inkiv: pysemnist, chyslova abo mnemonichna systema?: avtoref. dys. na zdobuttia nauk. stupenia kand. ist. nauk : spets. 07.00.02 «Vsesvitnia istoriia»/ Kupriienko Serhii Anatoliiovych - Kyiv, 2010. $-42 \mathrm{~s}$.

5. Le Taoïsme, essais. Bibliothèque de diffusion du Musée Guimet. // Journal Asiatique. - 1950. - C. 13-222.

6. Leibniz G. W. Explication de l'arithmétique binaire, qui se sert des seuls caractères $\mathrm{O} \& \mathrm{I}$ avec des remarques sur son utilité et sur ce qu'elle donne le sens des anciennes figures chinoises de Fohy / Gottfried Wilhelm Leibniz // MATHÉMATIQUE LEIBNITZ / Gottfried Wilhelm Leibniz. - Année: Académie royale des sciences, 1703 .

7. Leibnyts H. V. Trudi po fylosofyy nauky / Hotfryd Vylhelm Leibnyts. - M.: Lybrokom, 2010. - 178 s.

8. Lukianov A. E. Lao-tszы y Konfutsyi: Fylosofyia Dao / Anatolyi Evhenevych Lukianov. - M.: Vost. lyt., 2000. $-384 \mathrm{~s}$.

9. Primeglio. Introduccion al estudio de los quipos / Primeglio, C. Radicati di // Estudios sobre los quipus / Primeglio, C. Radicati di. - Lima: UNMSM, 2006. - C. 131-135.

10. Rezanenko V. F. Formalno-zmistovi vzaiemozviazky elementiv suchasnoi iierohlifichnoi pysemnosti: dys. dokt. fil. nauk: 10.02.15 / Rezanenko Volodymyr Fedorovych - Kyiv, 1996. - $431 \mathrm{~s}$

11. Wang H. Houcan Hanzi zhengti he bihua pinlv dui bihua renzhide yingxiang / H. Wang, J. Zhang, Zhang. // Sinica Acta Psychologica. - 2003. - №35.

12. Wing-tsit C. Instructions for practical living, and other Neo-Confucian writings / Chan Wing-tsit. - New York: Columbia University Press, 1963. -370 c.

13. 王陽明. 王守仁 撰, 吴光、钱明、董平、姚延福 编校 / 王陽明., 1992. - 1648 c.

14. Kalko R. Principles of algoritmization of machine translation in the theories of language evolution (based on the Ukrainian-English translation) / Rita Kalko. // International Journal of Advanced Research. - 2017. - №5. - C. 706-709. 